\title{
Landslide in a catchment area of a torrent and the consequences for the technical mitigation concept
}

\author{
F. J. Riedl \\ Austrian Federal Service for Torrent, Erosion and Avalanche Control, \\ District Office "Middle Inn Valley", Austria
}

\begin{abstract}
The focus of the following lies on the identification of the practical solutions by taking into account the theoretical background. A translational landslide occurred on October 2008 within an area of about 2.5 ha on the topographical left side of the torrent "Wattenbach" in Tyrol/Austria.

In the summer of 1965 a large debris flow event of the torrent "Wattenbach" happened and the underlying city of Wattens was completely destroyed. After this event several technical protection measurements were implemented to guarantee a certain factor of safety for the city of Wattens.

After the landslide event of 2008, the most important question concerned the interaction of the torrent "Wattenbach", the landslide and which reaction could be expected by a flooding event in the future.

To obtain certain quantitative and qualitative data, several analyses (modelling of the landslide by regarding different scenarios, laser scans, field works) were implemented and some of them are still going on.

Keywords: landslide, debris flow, torrent, Austrian Federal Service for Torrent, Erosion and Avalanche Control, technical protection measurements, natural hazards.
\end{abstract}

\section{Introduction}

\subsection{Austrian Federal Service for Torrent, Erosion and Avalanche Control, District Office "Middle Inn Valley"}

The main tasks of the Austrian Federal Service for Torrent, Erosion and Avalanche Control are divided into hazard zone planning (risk prevention), 
planning of technical mitigation measures against natural hazards, building constructions works and expertises for the public authorities.

The District Office "Middle Inn Valley", situated in Innsbruck, is responsible for the torrent, avalanche, rockfall and erosion protection in the two districts Innsbruck-Town and Innsbruck-Country. The total area covers 210.000 ha whereby only $15 \%$ of them can be used for permanent settlement.

There are also 256 torrent catchment areas and 264 harmful avalanche tracks which endanger the permanent settlement. In the year 2009 the monetary investments were about 5.0 million $€$ in the preventive technical, forestry and soil-bioengineering measurements.

\section{Landslide event on October 2008, city of Wattens, district of Innsbruck-Country}

\subsection{Kinematic analysis of the landslide in the catchment area of the torrent "Wattenbach"}

The landslide in the catchment area of the torrent "Wattenbach" occurred on October 2008 on the topographical left side of the torrent. For analysing purposes, a field work was conducted to obtain data about the geology, the geomorphology, the level of the mountain water, the surface runoff and the initial structural situation (brittle and ductile deformation, foliation, etc).

\subsubsection{Geology}

The geology is defined by a fine foliated phyllite, the so-called "Innsbrucker Quarzphyllite". In general, the northeast-exposed hillsides are ancient deep seated gravitational landslides which are nowadays in a nearly firm stage [1]. From the structural and tectonical point of view the phyllite was deformed by several different phases from D1-D4 [2]. Actually, a steady influence of the
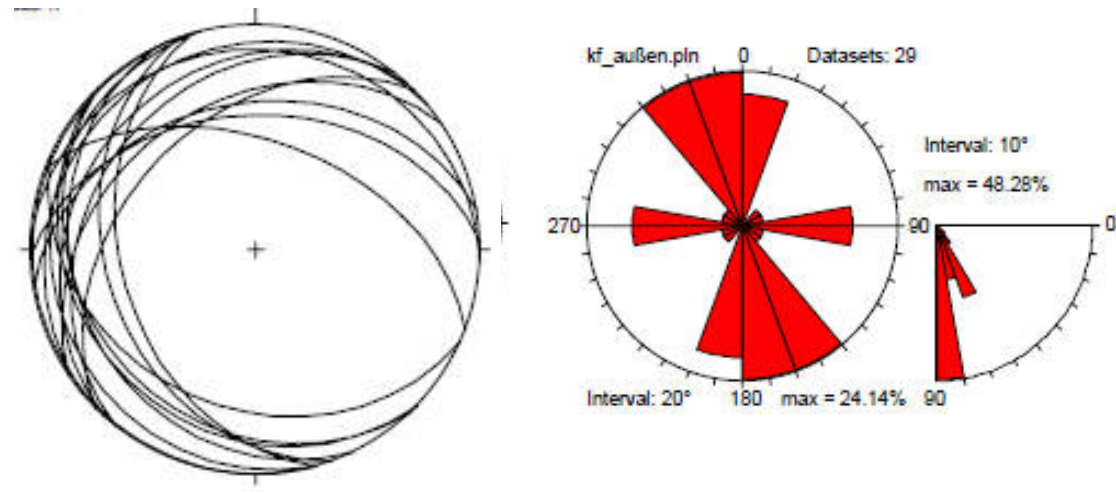

Figure 1: Orientation of the foliation and the brittle cracks within the landslide [3]. 

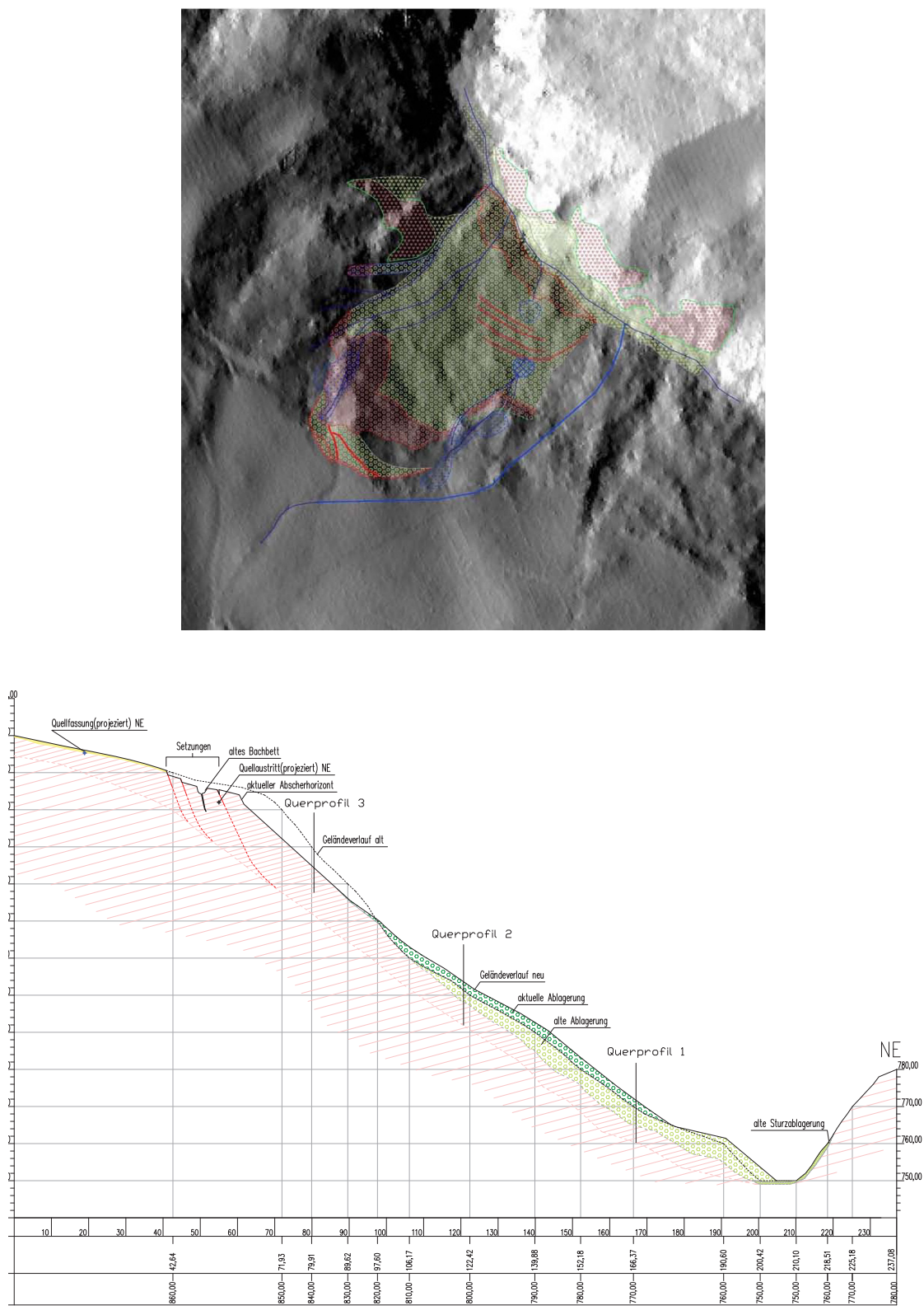

Figure 2: Geomorphological mapping and a profile through the active translational landslide [3]. 
active brittle sinistral Inntal fault can be examined which causes a negative structural influence on the stability of the preliminary deformed phyllite.

In this specific case the dip of the foliation diversifies, which is caused by a singular rotation, from south to west. Furthermore a nearly constant dip of the foliation to the southwest can be recognized. The brittle deformations within the landslide are characterized by steep northwest-southeast orientated cracks [3].

\subsubsection{Geomorphology}

From the kinematical point of view the landslide is a translational slide [4], partly within the solid rock, with a depth of the slip plane of about 10-20 m. As mentioned before the active landslide is part of an enlarged ancient deep seated gravitational landslide system. The torrent "Wattenbach" has eroded the convex front of the moving part during the last centuries and since the catastrophically debris flow event of 1965, the toe of the slope has become precipitous. The main scarp dips $50-70^{\circ}$ to the northeast and on the topographical right side of the boundary zones the dip of the scarp rotated to the north.

\subsubsection{Hydrogeological and hydrological runoff}

There are two diffuse hydrogeological mountain water zones, one between 850 $860 \mathrm{~m}$ a.s.l. and the other one between $810-820 \mathrm{~m}$ a.s.l. The hydrological surface

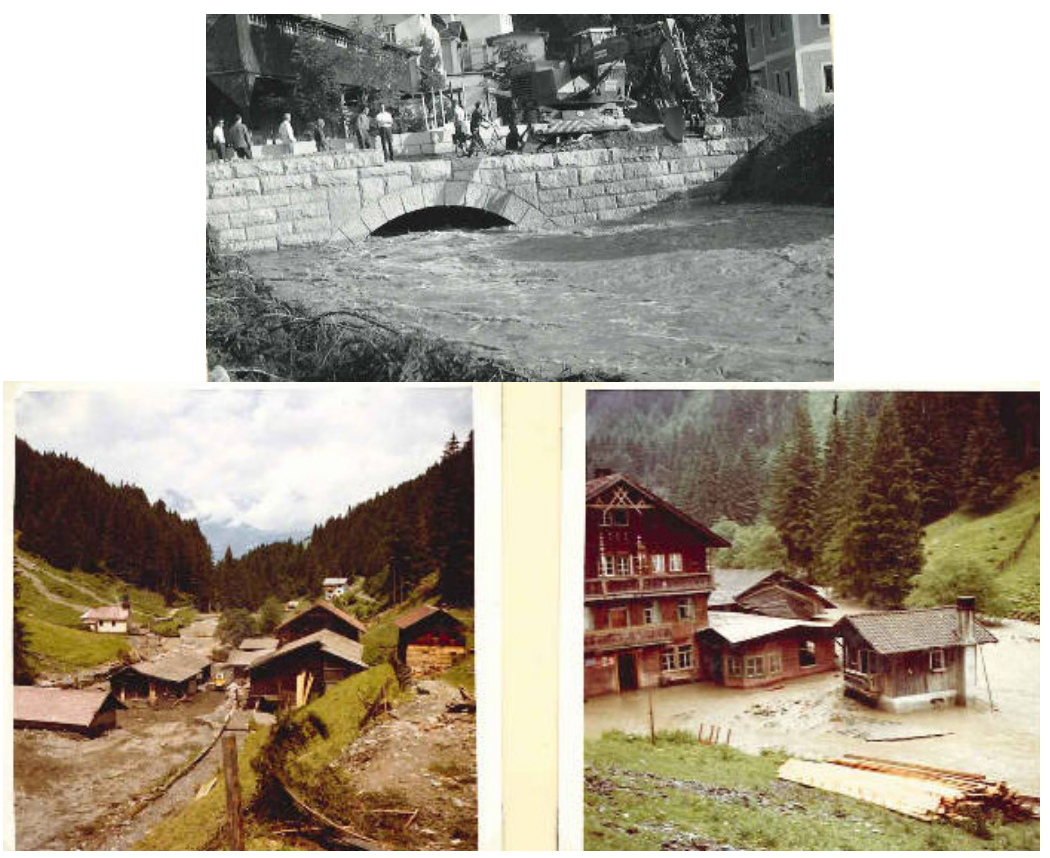

Figure 3: Debris flow event in August 1965 and the damages in the middle part of the torrent and the height of the water level by the bridge in the city of Wattens (above). 
Table 1: $\quad$ Results of the slope stability analysis.

\begin{tabular}{|c|c|c|c|}
\hline Szenarien & Kombination 1 & Kombination 2 & Kombination 3 \\
\hline a1 & 1,0 & 1,0 & 1,0 \\
\hline b1 & 1,0 & 1,0 & 0,90 \\
\hline b2 & 0,83 & 0,81 & 0,83 \\
\hline
\end{tabular}

Tabelle 1: Ergebnisse für die Berechnungen mit Gelāndeprofil 1

development of the landslide topographic profile 1 development of the landslide topographic profile 2 influence of the mountain water zone 1 by profile 1

\begin{tabular}{|c|c|c|c|}
\hline Szenarien & Kombination 1 & Kombination 2 & Kombination 3 \\
\hline $\mathrm{a} 2$ & 1,21 & 1,14 & 1,10 \\
\hline $\mathrm{c} 1$ & 1,10 & 1,10 & 1,08 \\
\hline $\mathrm{c} 2$ & 0,98 & 0,98 & 1,05 \\
\hline \hline $\mathrm{d} 1$ & 1,21 & 1,21 & 1,10 \\
\hline $\mathrm{d} 2$ & 1,21 & 1,21 & 1,10 \\
\hline
\end{tabular}
influence of the mountain water zone 2 by profile 1 decrease of the riverbed $5,0 \mathrm{~m}$ profile 2 decrease of the riverbed $10,0 \mathrm{~m}$ profile 2 increase of the riverbed $5,0 \mathrm{~m}$ profile 2 increase of the riverbed $10,0 \mathrm{~m}$ profile 2

Tabelle 2: Ergebnisse für die Berechnungen mit Gelāndeprofil 2

runoff is marked by several small gullies with some initial erosion. Local technical mitigation measures have been implemented by the Austrian Federal Service for Torrent, Erosion and Avalanche Control Service, District Office Middle Inn Valley on a tributary to the "Wattenbach".

The catchment area of the main torrent "Wattenbach" is $74 \mathrm{~km}^{2}$ with a peak runoff of about $90 \mathrm{~m}^{3} / \mathrm{s}$ with a regarded repeat period of time of 150 years. On the base of the hazard zone planning, the expected bed load is about $160.000 \mathrm{~m}^{3}$. The debris flow event of 1965, where large areas of the city Wattens were destroyed, the measured bed load was about $85.000 \mathrm{~m}^{3}$ [5].

The main drinking water spring of the city Wattens is above the active landslide on $920 \mathrm{~m}$ a.s.l. and the remaining water was currently flowing uncontrolled into the active moving zones.

\subsection{Geotechnical investigations and modelling}

The main tasks of the geotechnical investigations were to examine the development of the landslide, the role and importance of the mountain water level and the development of the landslide by decreasing and increasing the riverbed of the torrent "Wattenbach". The numeric modelling of the landslide, by regarding the topics, mentioned above, was done by an extern consulting engineering company with the finite element software PHASE2, Rocscience Inc. The results of this modelling should be the base for the further technical mitigation concept.

By analyzing the different scenarios (two topographical profiles and the influence of the two zones of the mountain water levels) the results of the slope stability analysis are as follows.

The main conclusion of these geotechnical investigations and the results of the varying scenarios were the fact that a decrease of the riverbed of the torrent "Wattenbach" with more than $10,0 \mathrm{~m}$ would lead to a slope failure (c2). This 
180 Monitoring, Simulation, Prevention and Remediation of Dense and Debris Flows III

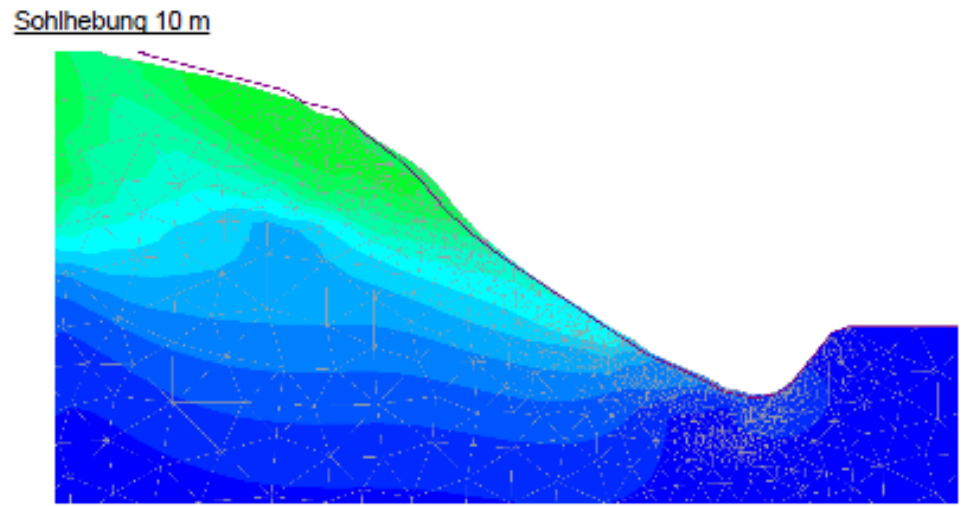

Abbildung 42: Grenzzustand des Hanges (Deformationen farblich dargestellt)

Figure 4: Modelling of the landslide and the deformation by regarding the different scenarios.
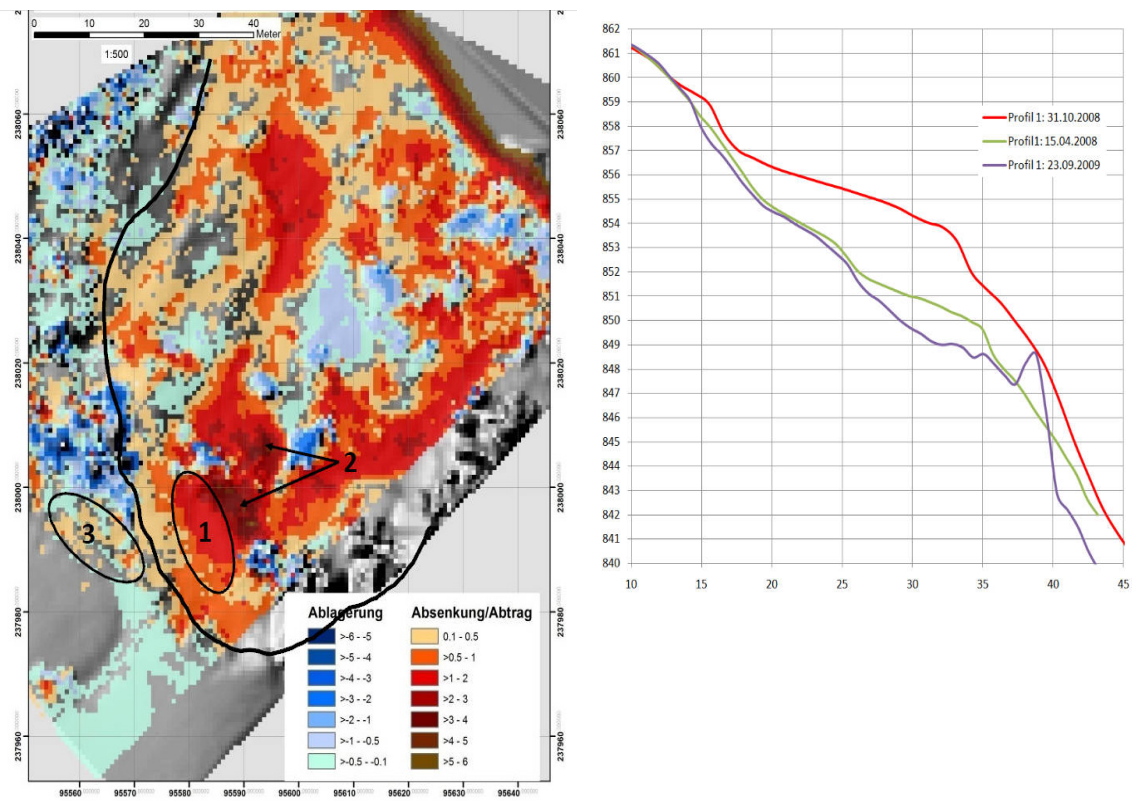

Figure 5: Difference in height inside the landslide and the distinctive depression in the upper part [7]. 
induces to a technical mitigation concept whereby the riverbed has to be fixed against depth erosion. An increase of the riverbed results in a minor increase of the factor of safety $(\mathrm{d} 1-\mathrm{d} 2)$. Nevertheless the mountain water level is fundamental and has to be considered for the further mitigation planning [6].

\subsection{Laser scanning of the landslide}

In the alpine regions the original use of the laser scanning is based on the examination of the snow cover. The scanning of a surface of a landslide and the obtained experiences for the future was one of the defined tasks. A cooperation partner, the Federal Research and Training Centre for Forests, Natural Hazards and Landscape, has fulfilled on base of a cooperation contract the laser scanning of this landslide. The scanning was done with the Scanner LPM98-2K by the company Riegl with the highest cancelation and a projected spot spacing of $0,75 \mathrm{~m}[7]$.

The focus of the laser scanning investigation was to obtain compressions and depressions within the active zones and further detailed information about the kinematical movements. It is also important to point out the fact that the technical mitigation achievements should be quantified after finishing the construction works for a defined period of 3-4 years. The reference measurement has already been created after the event 2008 and the main confiding at this time were the enormous depressions on the upper part of the landslide up to $6,0 \mathrm{~m}$.

\section{Technical mitigation concept}

\subsection{General conspectus}

On the base of the several investigation results, the technical mitigation concept was according to them.

The main conclusion of the slope simulation was the fact that the riverbed should be fixed and consolidated to obtain slope stability. Due to the induced depth erosion, caused by the debris flow event in den "Wattenbach" in the summer of 1965, a collapse of the slope stability could occur and additionally bed load material could be transported up to the city of Wattens.

\subsection{Consolidation of the riverbed of the torrent "Wattenbach"}

For the stabilisation and consolidation process of the riverbed of the torrent "Wattenbach", at least 13 check dams with a certain debris flow section will be constructed to avoid depth erosion during a debris flow event. The dimension of the check dams will be designed on the peak runoff of $90 \mathrm{~m}^{3} / \mathrm{s}$. The needed height of the check dams is about $3-4 \mathrm{~m}$, the concrete cubature is about $300 \mathrm{~m}^{3}$ and the steel demand is about 8,5 tonnes per check dam. The toe of the landslide should be firm up by stabilizing the riverbed through these check dams. 


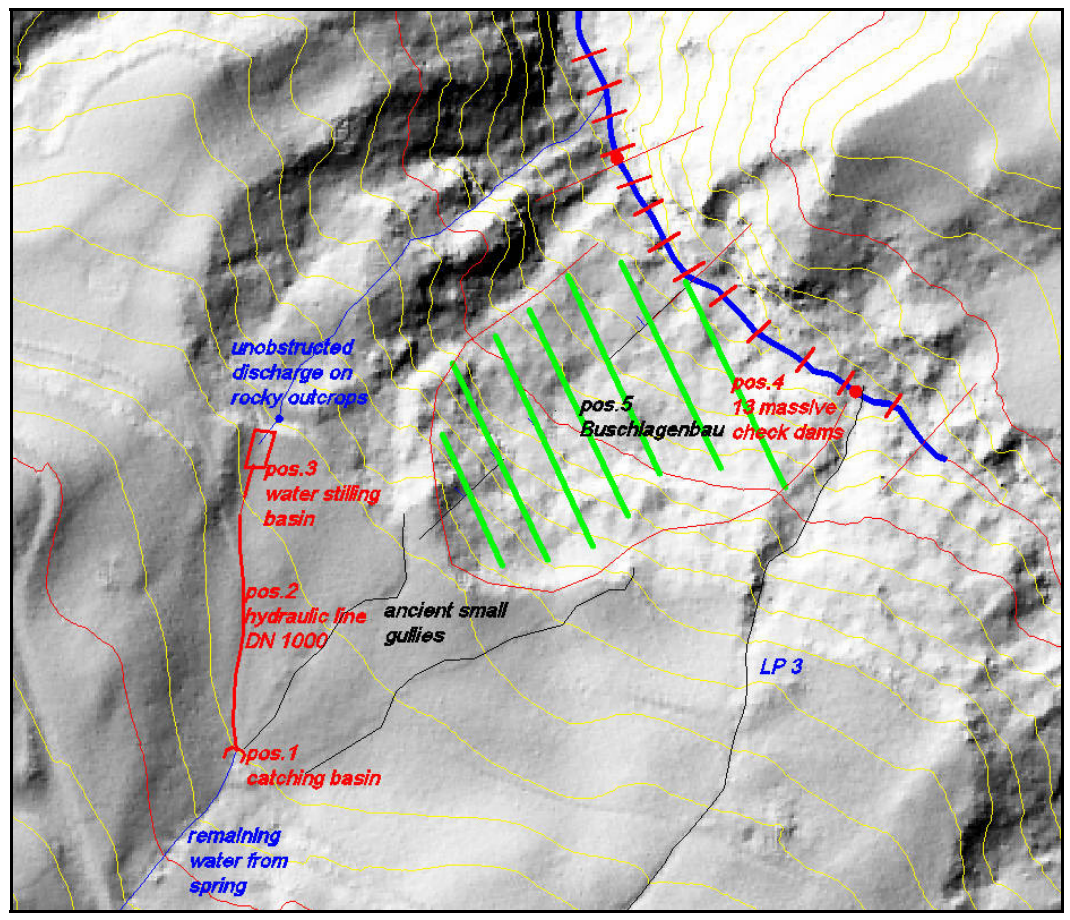

Figure 6: Technical mitigation concept at the basis of the investigations.

\subsection{Hydrological surface runoff of the small gullies}

The small gullies beyond the landslide, which infiltrated into the instable slope, will be displaced with an earth-covered hydraulic line DN1000 to the rocky outcrops on the topographical left side of the landslide.

To decrease the kinematic force of the water, a stilling basin will be constructed on base of the hydraulic dimension. Due to the rocky outcrops the surface runoff of the small gullies can then be discharged unobstructed on them.

\subsection{Soil-bioengineering measurements}

The diffuse characteristic of the two mountain water zones within the landslide will be conceived by soil-bioengineering measurements, the so-called "Buschlagenbau" [8]. Differential salix are used for the "Buschlagenbau" and they will be orientated to the topographical left rocky outcrops, to achieve a twodimensional drainage effect. Another aspect of the "Buschlagenbau" is a small area stabilisation of the upper soil-complex. These soil-bioengineering measurements are the highly recommendable measurements due to uncontrolled diffuse water flow. The main mechanical movements of an unstable slope are in general caused by such diffuse water flows. 


\subsection{Perspectives}

To obtain the expected achievements of this technical mitigation concept it is mandatory to make further investigations in analyzing the landslide with the laser scanning after finishing the construction works. The quantitative and qualitative movements of the investigation points will give an explanation of the landslide and a confirmation if the technical measurements worked as successfully as expected.

\section{References}

[1] Hermann, S., Tiefreichende Großhangbewegungen im Kristallin der Niederen Tauern, Ostalpen. -Verbreitung, Typen und ihr Einfluss auf die Morphogenese alpiner Täler. Geoforum Umhausen (GFU), 1; Innsbruck, 1999

[2] Rockenschaub, M., Kolenprat, B., Frank, W., The tectonometamorphic evolution of Austroalpine units in the Brenner area (Tirol, Austria) - new geochronological implications. Tübinger Geowissenschaftlichen Arbeiten, Series A, Vol. 52, pp. 118-119, 1999.

[3] i.n.n., Rutschung Eggerbachl - Bewertung des Ist-Zustandes und Abschätzung der Auswirkungen auf den Hochwasserabfluss im Wattenbach. Intern Report, Innsbruck, 2009.

[4] Varnes, D. J., Slope Movement Types and Processes - in: Special Report 176: Landslides: Analysis and Control, (R. L. Schuster and R. J. Krizek, eds.), TRB, National Research Council, Washington D.C, 1978.

[5] Forsttechnischer Dienst für Wildbach- und Lawinenverbauung, Wattenbach. Kollaudierungsoperat 1993 für die Baujahre 1965-1991, Technischer Bericht, pp. 21, Innsbruck, 1993

[6] GEC ZT GmbH, Rutschung Wattenbach/Eggerbach. Intern Report, Innsbruck, 2009.

[7] Federal Research and Training Centre for Forests, Natural Hazards and Landscape Department Natural Hazards and Alpine Timberline Unit Water Balance in Alpine Catchments. Kurzinformation zur Massenbewegung Wattental, Laserscanning, Intern Report, Innsbruck, 2009.

[8] Schiechtl, M., Stern, R., Handbuch für naturnahen Erdbau, Österreichischer Agrarverlag: Wien, pp. 92-96, 1992. 